\title{
Low rate of placental pathological examination in a tertiary care hospital in Sana'a, Yemen
}

A.H. Al Harazi ${ }^{1}$ and K.A. Frass ${ }^{2}$

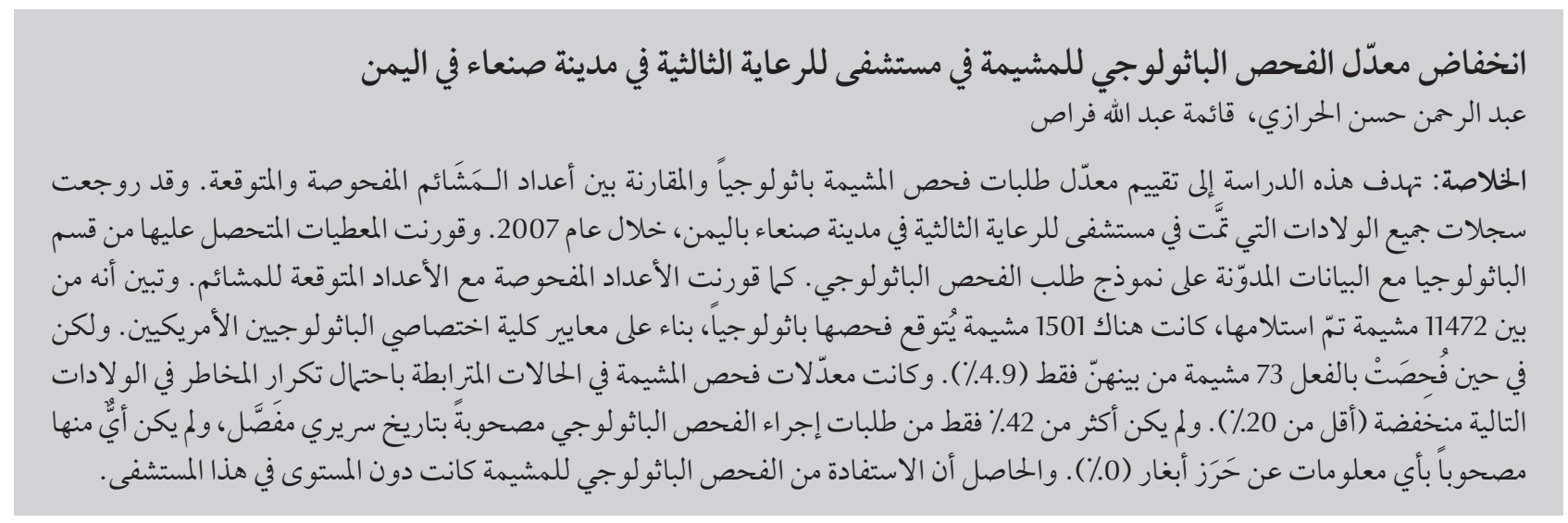

ABSTRACT The aim of this study was to evaluate the rate of submission of placentas for pathological examination and compare the observed and expected numbers of placentas submitted. Records were reviewed for all deliveries occurring at a tertiary care hospital in Sana'a, Yemen, during 2007. Data from pathology department records were compared with data on pathology request forms. The observed and expected numbers of placentas examined were compared. Of 11472 placentas delivered, 1501 were expected to be pathologically examined, based on College of American Pathologists indications. Only 73 of these (4.9\%) had actually been examined. The examination rates for conditions associated with the possible recurrence risks in the subsequent pregnancies were low, below $20 \%$. Only $42 \%$ of the pathology request forms gave detailed clinical histories and $0 \%$ gave information about Apgar scores. Placental pathological examination was under-utilized in this hospital.

Faible taux d'examen pathologique du placenta dans un hôpital de soins de santé tertiaires à Sanaa (Yémen)

RÉSUMÉ La présente étude a évalué le nombre de placentas soumis à un examen pathologique et l'a comparé avec le nombre de placentas qui auraient dû être soumis à cet examen. Les dossiers de tous les accouchements pris en charge en 2007 dans un hôpital de soins de santé tertiaires de Sanaa (Yémen) ont été étudiés. Les données des dossiers du service de pathologie ont été comparées avec celles des formulaires de demande d'examen pathologique. Le nombre de placentas examinés et le nombre de placentas attendus ont été comparés. Sur 11472 placentas, 1501 auraient dû être soumis à un examen pathologique, selon les recommandations du College of American Pathologists. Dans les faits, seuls 73 d'entre eux (4,9\%) avaient été examinés. Les taux de recherche de pathologies associées à des risques de récurrence au cours des grossesses ultérieures étaient faibles, inférieurs à $20 \%$. Seuls $42 \%$ des formulaires de demande d'examen pathologique donnaient des précisions sur les antécédents cliniques et aucun formulaire $(0 \%)$ ne fournissait d'information sur le score d'Apgar. L'examen pathologique du placenta était sous-utilisé dans cet hôpital.

'Department of Obstetrics and Gynaecology, Faculty of Medicine, University of Dhamar, Dhamar, Yemen (Correspondence to A.H. Al Harazi: yem008@yahoo.com).

${ }^{2}$ Department of Obstetrics and Gynaecology, Faculty of Medicine, University of Sana'a, Sana'a, Yemen.

Received: 02/07/09; accepted: 05/10/09 


\section{Introduction}

Pathological examination of the placenta has the potential to clarify the pathophysiology of an adverse pregnancy outcome, to help improve the management of the mother's subsequent pregnancies and to assist in the medicolegal assessment of an adverse outcome [1]. It also helps to understand any antenatal and intrapartum events that contribute to long-term neurodevelopment morbidities [2].

In 1991 the College of American Pathologists (CAP) reported a list of maternal, fetal and neonatal and placental conditions for which gross and microscopic placental examination was recommended [3]. However, most hospitals do not follow these recommendations. Instead, the delivering physician is usually responsible for determining when pathological interpretation of the placenta is indicated [4]. The prevalence of such examination is frequently low in most hospitals. A survey of practices showed that most pathology departments (71\%) examined $25 \%$ or fewer of the placentas delivered at their institutions [5]. Badawi et al. in Australia found that placentas were examined in only $11.2 \%$ of cases and $0.7 \%$ of controls fulfilling the (maternal or fetal) criteria for placental examination [6].

The aim of this study in Yemen was to evaluate the rate of submission of placentas for pathological examination in a tertiary care hospital in Sana'a and compare the observed numbers sent for examination with the expected numbers according to CAP indications.

\section{Methods}

Al-Thawra general hospital in Sana'a, Yemen, is a tertiary care level hospital. Submission of placentas for pathology depends totally on the decision of the delivering physician. There are no hospital guidelines regarding pathological examination of the placenta, and the pathology of the placenta is often not part of the teaching programme given for the staff at the hospital.

Data for this study were obtained from the hospital pathology department records, which contained details of all placentas submitted from the delivery room from 1 January to 31 December 2007. These included the mother's name, date of submission, indications for examination and a summary of the results. The data were collected and compared with the information presented on the pathology request forms. The request forms were assessed for 4 points: indications for placental examination, gestational age, clinical history of the mother and Apgar scores.

The hospital outcome records were reviewed for all 11472 deliveries at the hospital during the study period. We categorized the indications for placental examination into 12 categories according to CAP guidelines ( 7 for recommended maternal indications; 2 for other maternal indications; and 3 for recommended fetal and neonatal indications). All deliveries matching these conditions were taken as the expected number of placentas. Placentas actually sent for pathology were classified in the same way for examination to give the observed number. The demographic data of each woman whose placenta was examined were obtained.

Data were computed and analysed using the Medcalc statistical programme. The data were expressed as mean and standard deviation (SD). Percentages were used when appropriate. The observed and expected percentages of placentas examined pathologically were compared. The difference between the 2 population values was considered significant at $P<0.05$.

\section{Results}

During the year 2007, there were 11472 placentas delivered at Al-Thawra general hospital for neonates between
28 and 42 weeks of gestation. Of these, records showed that 1501 placentas met the CAP criteria for pathological examination. Only 73 of these placentas (4.9\%) had actually been examined. The difference between the expected and observed rate of placental examination was statistically significant $(P=0.003)$. The demographic data of the women who had and had not had their placentas examined are summarized in Table 1 according to the $12 \mathrm{CAP}$ indications.

Evaluation of the information given in the pathology request forms revealed that $96 \%$ stated the indications for pathology, $42 \%$ gave a detailed clinical history of the mothers and $0 \%$ gave information about the Apgar score. Table 2 shows the examination rates for each indication. The placental examination rates for cases of premature labour, stillbirth and those with more than 2 previous miscarriages were $16.8 \%, 13.6 \%$ and $7.8 \%$ respectively.

\section{Discussion}

Only 73 out of 1501 placentas (4.9\%) fulfilling the CAP criteria for pathology examination were actually examined in the hospital. Spencer and Khong found that one-third of placentas that should have been examined were examined [1]. However, our finding was considerably lower than this figure.

In our hospital, the indications for placental examination are dependent on the decision of the delivering physician. For this reason, we were unable to determine if such indications were valued and followed by all clinicians. There are instances when one clinician decides to examine the placenta under a particular indication whereas another would not [3]. Thus, we diagnosed the cases using CAP guidelines. We noted that the examination rates for some conditions associated with the possible risk of recurrence in subsequent pregnancies were very low, below $20 \%$. For example, the placental examination rates for cases of 


\begin{tabular}{|c|c|c|c|c|c|}
\hline \multirow[t]{2}{*}{ Variable } & \multicolumn{2}{|c|}{$\begin{array}{l}\text { Placenta examined } \\
\qquad(n=73)\end{array}$} & \multicolumn{2}{|c|}{$\begin{array}{l}\text { Placenta not examined } \\
(n=1428)\end{array}$} & $P$-value \\
\hline & \multicolumn{2}{|c|}{ Mean (SD) } & \multicolumn{2}{|c|}{ Mean (SD) } & \\
\hline Maternal age (years) & \multicolumn{2}{|c|}{$27.2(6.1)$} & \multicolumn{2}{|c|}{$27.5(4.7)$} & 0.5649 \\
\hline Gravidity (No.) & \multicolumn{2}{|c|}{$1.35(0.56)$} & \multicolumn{2}{|c|}{$1.50(0.56)$} & 0.7853 \\
\hline \multirow[t]{2}{*}{ Gestational age (weeks) } & \multicolumn{2}{|c|}{$35.7(3.9)$} & \multicolumn{2}{|c|}{$36.8(7.1)$} & 0.1893 \\
\hline & No. & $\%$ & No. & $\%$ & \\
\hline \multicolumn{6}{|l|}{ Outcome } \\
\hline Alive & 39 & 53.4 & 889 & 62.3 & \\
\hline Stillborn & 34 & 46.6 & 539 & 37.7 & \\
\hline \multicolumn{6}{|l|}{ Mode of delivery } \\
\hline Vaginal & 64 & 87.7 & 1255 & 87.9 & \\
\hline Caesarean & 9 & 12.3 & 173 & 12.1 & \\
\hline
\end{tabular}

$S D=$ standard deviation.

premature labour, stillbirth and those with more than 2 previous miscarriages were $16.8 \%, 13.6 \%$ and $7.8 \%$ respectively.

The low submission rate of placental examination in this hospital indicates that the practice was not considered useful by most physicians. It is likely that the lack of clear and teachable guidelines might negatively affect the appreciation of the clinical value of such practice. There is a general lack of interdepartmental communication between obstetricians and pathologists. Lack of communication between obstetricians and pathologists indicate a failure to use the information provided for each case studied. The absence of standard criteria and terms for each placental lesion used by the pathologists, combined with a lack of awareness of the need for examination may contribute to discouraging obstetricians from submitting placental tissues.

Most pathology reports in this hospital use histological terms that are often unfamiliar to obstetricians and not linked clinically to the underlying disease. Sun et al. stated that placental and perinatal pathology is rarely part

\begin{tabular}{|c|c|c|}
\hline Indication & $\begin{array}{l}\text { No. examined/no. } \\
\text { indicated }\end{array}$ & $\begin{array}{l}\text { Examination } \\
\text { rate (\%) }\end{array}$ \\
\hline Premature delivery $\leq 34$ weeks gestation & 26/155 & 16.8 \\
\hline Stillbirth or perinatal death & $11 / 81$ & 13.6 \\
\hline Severe oligohydramnios & $7 / 70$ & 10.0 \\
\hline $\begin{array}{l}\text { Unexplained or recurrent pregnancy } \\
\text { complication }\end{array}$ & $8 / 102$ & 7.8 \\
\hline Gestational age $42+$ weeks & $5 / 101$ & 5.0 \\
\hline Severe hypertensive disorder & $2 / 460$ & 0.4 \\
\hline Placental abruption & $1 / 89$ & 1.1 \\
\hline Unexplained 3rd trimester bleeding & $1 / 146$ & 0.7 \\
\hline Severe unexplained polyhydramnios & $3 / 90$ & 3.3 \\
\hline Major congenital anomaly & $5 / 77$ & 6.5 \\
\hline Thick or viscid meconium & $3 / 113$ & 2.7 \\
\hline Hydrops fetalis & $1 / 17$ & 5.9 \\
\hline Total & 73/1501 & 4.9 \\
\hline
\end{tabular}

of the residency training programme in either pathology or obstetrics, resulting in a lack of mutual vocabulary and poor communication between pathologists and obstetricians $[2,7]$. As the indications for microscopic placental examination listed by CAP guidelines are not always used in most hospitals [1,2], each institution should have its own explicit practice guidelines based on the best available evidence and communicated to the staff. Emphasis on increasing the experience and improving the diagnostic ability of the hospital pathologist could help encourage obstetricians to submit placentas for examination, particularly for high-risk cases. Redline et al. emphasized that it is important for each lesion to be defined by unambiguous histological terms and subclassified according to severity, duration, extent and type of involvement [8]. Also enhancement of the pathologist's feedback could help avoid errors, and improve the pathologist's ability to diagnose the underlying lesions.

Despite using checklist pathology request forms, there were inadequate clinical histories in $58 \%$ of cases. Failure to provide adequate information useful for understanding the current and previous pregnancyscenarios could affect the interpretation of placental examination findings and therefore hamper meaningful results. In our study the Apgar score 
was not recorded at all. Placental examination can help determine whether the cause of death (when acute) is related to underlying pathological processes or caused by fetal distress unrecognized by the physician.

\section{Conclusion}

A very small proportion of placentas that met the CAP indications for pathological examination were actually examined in this hospital.
Agreed and explicit hospital guidelines detailing when to submit placentas to the pathology department for examination are needed. These are particularly important with regard to high-risk cases.

\section{References}

1. Spencer MK, Khong TY. Conformity to guidelines for pathologic examination of the placenta. Archives of Pathology and Laboratory Medicine, 2003, 121:205-207.

2. Sun CJ et al. Discrepancy in pathologic diagnosis of placental lesions. Archives of Pathology and Laboratory Medicine, 2002, 126:709-709.

3. Curtin WM et al. Pathologic examination of the placenta and observed practice. Obstetrics and Gynecology, 2007, 109:35-41.

4. Joseph FY. Examination of placenta. American Family Physician, 1998, 57(5):1045-1054.
5. Gersell DJ, American Society of Clinical Pathologists. ASCP survey on placental examination. American Journal of Clinical Pathology, 1998, 109:127-143.

6. Badawi $\mathrm{N}$ et al. Why is the placenta being ignored? Australian and New Zealand Journal of Obstetrics and Gynaecology, 2000, 40:343-346.

7. Salafia CM, Vintzileos AM. Why all placentas should be examined by a pathologist in 1990. American Journal of Obstetrics and Gynecology, 1990, 163:1282-1293.

8. Redline RW et al. Placental diagnostic criteria and clinical correlation-a workshop report. Placenta, 2005, 26(Suppl. A):S114-117.

\section{Gender, women and primary health care renewal: a discussion paper}

This discussion paper brings together evidence and experience from around the world focusing on making health systems more gender responsive. The paper uses a framework that combines WHO's six building blocks for health systems and the primary health care reforms propounded in the World Health Report 2008 on primary health care. Furthermore, the paper provides examples of what has worked and how, and ends with an agenda for action to strengthen the work of policy-makers, their advisers and development partners as well as practitioners as they seek to integrate gender equality perspectives into health systems strengthening, including primary health care reforms.

This paper can be accessed at: http://www.who.int/gender/documents/women_and_girls/9789241564038/en/ index.html 